How to cite this article:

Musliza Mat Jusoh, M., Ismail, S. N, Anis Salwa Abdullah, A. S. (2020). Efikasi kendiri guru sebagai mediator terhadap hubungan antara iklim sekolah dan komitmen guru. Practitioner Research, 2, 137-162.

\title{
EFIKASI KENDIRI GURU SEBAGAI MEDIATOR TERHADAP HUBUNGAN ANTARA IKLIM SEKOLAH DAN KOMITMEN GURU
}

\author{
Musliza Mat Jusoh ${ }^{1}$, Siti Noor Ismail ${ }^{2}$ \& \\ Anis Salwa Abdullah ${ }^{3}$ \\ ${ }^{1,2,3}$ School of Education and Modern Languages, \\ Universiti Utara Malaysia
}

Corresponding author:*muslizabtmatjusoh78@gmail.com

Received: 29/06/2020 Revised: 20/07/2020 Accepted: 10/08/2020 Published: 06/09/2020

\begin{abstract}
ABSTRAK
Iklim sekolah yang positif akan menghasilkan modal insan berkualiti tinggi, sementara keberkesanan diri bertindak sebagai pendorong untuk mencapai matlamat. Keberkesanan kedua-dua elemen ini meningkatkan komitmen guru dalam memastikan kejayaan institusi pendidikan. Oleh itu, kajian yang dikembangkan untuk mengkaji hubungan antara iklim sekolah dan komitmen guru, serta hubungan tidak langsung melalui keberkesanan diri sebagai konstruk mediator. Guru dipilih secara rawak dari 18 sekolah menengah berpencapaian tinggi di Kelantan, dengan jumlah keseluruhan 360 responden. Kaedah tinjauan keratan rentas diterapkan untuk mengumpulkan data. Soal selidik terdiri daripada 44 item. Perisian IBM SPSS digunakan untuk menganalisis ujian korelasi dan regresi. Analisis korelasi Pearson mengesahkan hubungan positif dan signifikan antara ketiga-tiga pemboleh ubah, iaitu korelasi lemah untuk iklim sekolah dan komitmen $(r=.24, p<.01)$, serta antara iklim sekolah dan keberkesanan diri $(r=.23, p<.01)$. Sebaliknya, korelasi tinggi antara keberkesanan diri dan komitmen $(r=.85, p<.01)$. Analisis regresi terhadap pengaruh iklim sekolah terhadap komitmen guru
\end{abstract}


menunjukkan bahawa $R 2=.06, p<.01$ adalah signifikan. Nilai beta menunjukkan bahawa iklim sekolah menyumbang 0.24 (24\%), yang mempengaruhi komitmen secara signifikan. Analisis regresi berganda terhadap iklim sekolah dan efikasi kendiri terhadap komitmen guru mengesahkan bahawa $R 2=.72, p<.01$ adalah signifikan. Walau bagaimanapun, nilai beta menunjukkan bahawa sumbangan iklim sekolah menurun menjadi 0,05 (5\%) dan tidak mempengaruhi komitmen secara signifikan kerana peramal keberkesanan diri dimasukkan ke dalam model regresi. Nilai beta menunjukkan bahawa keberkesanan diri menyumbang 0.84 (84\%), secara signifikan mempengaruhi komitmen dan bertindak sebagai pemboleh ubah mediator penuh untuk iklim sekolah dan komitmen guru. Dapatan kajian ini mencadangkan hubungan iklim sekolah yang signifikan untuk meningkatkan keberkesanan dan komitmen diri guru. Kajian ini juga memberikan sumbangan yang signifikan terhadap teori dan peluasan pengetahuan dengan menjelaskan peranan iklim sekolah dalam meningkatkan komitmen guru, dan juga menyoroti peranan mediator efikasi kendiri yang mempunyai pengaruh yang signifikan terhadap komitmen guru juga.

Kata Kunci: Keberkesanan diri, Iklim sekolah, Komitmen, Guru, Sekolah menengah, Mediator

\section{ABSTRACT}

The Ministry of Education Malaysia aims to develop an educational system that is capable in improving achievement and innovation. This goal requires high commitment and precision from all parties, especially teachers that play the main role in educational institutions. Thus, a positive school climate will produce high-quality human capital, while self-efficacy acts as a driving force to pursue the goals. The effectiveness of these two elements enhances the commitment of teachers in order to ensure the success of educational institutions. This study was developed to examine the relationship between school climate and teacher commitment, as well as the indirect relationship through self-efficacy as a mediator construct. Teachers were selected randomly from 18 high-achievement secondary schools in Kelantan, with a total of 360 respondents. A cross-sectional survey method was applied to collect data. The questionnaire consisted of 44 
items. The IBM SPSS software was used to analyze the correlation and regression tests. The Pearson correlation analysis confirmed positive and significant relationships between the three variables, namely the weak correlation for school climate and commitment $(r=.24, p<.01)$, as well as between school climate and self-efficacy $(r=.23, p<.01)$. In contrast, the correlation was high between selfefficacy and commitment $(r=.85, p<.01)$. Regression analysis for the effect of school climate on teacher commitment showed that $R^{2}=.06$, $p<.01$ was significant. The beta value showed that the school's climate contributed $\beta=.24$ (24\%), significantly affecting commitment. Multiple regression analysis of school climate and self-efficacy on teacher commitment confirmed that $R^{2}=.72, p<.01$ was significant. However, beta values showed that school climate contribution decreased to 0.05 (5\%) and did not significantly affect commitment as the self-efficacy predictor was included in the regression model. The beta value showed that self-efficacy contributed 0.84 (84\%), significantly influencing commitment and acting as a full mediator variable for school climate and teachers' commitment. The finding of this study proposes significant school climate relationships to enhance teachers' self-efficacy and commitment. This study also contributes significantly to the theory and the extension of knowledge by explaining the role of school climate in enhancing teachers' commitment, as well as highlighting the mediator role of self-efficacy that has a significant effect on teacher commitment as well. Therefore, the school administrators should provide a better, condusive school climate to encourage higher self-efficacy among teachers, through self-confidence in group guidance, student assignments, innovative education and attitude towards homework. As a result, teachers could have more opportunity to develop their commitment to schools.

Keywords: Self-efficacy, School climate, Commitment, Teachers, Secondary schools, Mediator

\section{PENGENALAN}

Transformasi pendidikan dalam Pelan Pembangunan Pendidikan Malaysia (PPPM) 2021-2025 yang dihasratkan oleh Kementerian Pendidikan Malaysia (KPM) adalah luas dan rencam. Justeru, sebagai persediaan pelaksanaan gelombang ketiga, iaitu bagi menganjak 
ke arah kecemerlangan melalui peningkatan keluwesan operasi, budaya kecemerlangan profesional keteladanan rakan setugas perlu dipupuk (KPM, 2012). Guru dan pemimpin sekolah harus sentiasa memberikan komitmen yang baik dalam menyediakan bimbingan, berkongsi amalan terbaik, dan memastikan rakan setugas mempunyai kebertanggungjawaban memenuhi standard profesional.

Maka, bagi mencapai tujuan tersebut, pemimpin sekolah perlu sentiasa memastikan iklim sekolah adalah kondusif agar para guru dapat bekerja dalam keadaan yang sejahtera. Keadaan iklim sekolah yang positif berperanan penting dalam menghasilkan modal insan yang berkualiti tinggi, yang secara tidak langsung mendorong ke arah penambahbaikan dan peningkatan sistem pendidikan di negara kita, di samping membina sikap kerja dan komitmen guru terhadap organisasi (Wan Ismail \& Kassim, 2015).

Selain itu, efikasi kendiri merupakan tahap keyakinan dan tingkah laku yang hadir secara individu untuk melaksanakan tugas-tugas tertentu dengan berkesan. Maka kepercayaan seseorang adalah berdasarkan kemampuan untuk melakukan tindakan yang diperlukan (Bandura, 1995). Malah, harga diri dalam bentuk kemampuan diri yang mempengaruhi tingkah laku untuk mencapai matlamat (Johari, Ismail, Osman, \& Othman, 2009) mampu merangsang komitmen guru yang telah terbukti berupaya mempengaruhi kejayaan sesebuah organisasi atau sekolah (Daud, 2007).

\section{PENYATAAN MASALAH}

Banyak kajian menunjukkan bahawa komitmen guru masih menunjukkan hasil yang pelbagai. Shafiq dan Rana (2016) mendapati bahawa kebanyakan guru menolak untuk melibatkan diri dalam profesion perguruan sebagai pilihan pertama, malah menjadikannya sebagai salah satu pilihan terakhir. Di samping itu, tahap komitmen organisasi guru juga rendah kerana profesion guru dianggap memikul tanggungjawab yang besar namun berada pada tahap standard yang rendah.

Selain itu, komitmen kerja guru menunjukkan terdapat hubungan yang signifikan pada aras sederhana di sekolah berprestasi tinggi, 
dan pada aras lemah di sekolah berprestasi rendah, terutamanya jika difokuskan kepada dimensi-dimensi tertentu. Guru-guru di sekolah menengah berprestasi tinggi mempunyai komitmen terhadap pengajaran pada tahap tinggi, iaitu guru lebih memfokuskan kepada pengajaran dan pembelajaran di dalam bilik darjah. Bahkan, komitmen terhadap pengajaran ini telah membawa kepada pencapaian akademik pelajar yang tinggi. Namun, tugasan yang semakin bertambah akan menimbulkan masalah yang boleh membawa kepada meningkatnya tekanan kerja, seterusnya mempengaruhi komitmen dan kepuasan kerja guru (Mohamad, Kasim, Zakaria \& Mohd Nasir, 2016). Malah, guru dengan tahap komitmen yang rendah akan menimbulkan masalah kepada pihak pentadbiran sekolah umumnya dan kepada ketua khasnya (Hallinger \& Heck, 2010).

Mohd. Yusof dan Saidin (2017) pula mendapati bahawa walaupun iklim sekolah berada pada tahap tinggi, tahap komitmen guru masih berada pada tahap sederhana. Komitmen guru juga mempunyai hubungan yang positif dengan iklim sekolah secara signifikan namun hubungan tersebut adalah sederhana. Tambahan pula, komitmen organisasi juga menunjukkan perbezaan mengikut jenis sekolah (Jazmi, 2015). Justeru, prestasi pencapaian akademik pelajar yang tidak selari dengan tahap komitmen guru yang tinggi di sekolah berprestasi rendah, menunjukkan terdapatnya faktor peramal lain yang turut mempengaruhi pencapaian akademik pelajar. Faktor budaya dan iklim sekolah berkemungkinan merupakan peramal terhadap pencapaian sekolah memandangkan budaya dan iklim sekolah yang positif lebih dipraktikkan di sekolah berprestasi tinggi berbanding di sekolah berprestasi rendah, serta mempunyai hubungan yang positif dengan pencapaian akademik pelajar (Daud, 2007; Mohamad, Kasim, Zakaria \& Mohd Nasir, 2016).

Selain iklim sekolah, efikasi kendiri turut dilihat sebagai faktor penting dan besar pengaruhnya dalam menentukan keupayaan dan kecekapan guru dalam menjalankan tugas dan tanggungjawab.

Guru-guru yang tidak dapat melakukan adaptasi terhadap iklim sekolah akan memberikan kesan terhadap efikasi kendiri dan prestasi kerja (Haron, Wan Jaafar, \& Jaafar, 2010). Tambahan pula, efikasi kendiri telah dikesan berupaya menjadi pemboleh ubah mediator yang baik (Mansor \& Dali, 2016; Hauschildt \& Konradt, 2012). Maka, 
kajian ini dilaksanakan untuk mengenal pasti tahap iklim sekolah, efikasi kendiri dan komitmen, serta hubungan dan peranan ketiga-tiga pemboleh ubah tersebut di sekolah menengah berprestasi tinggi di Kelantan.

\section{TINJAUAN LITERATUR}

\section{Komitmen}

Komitmen guru juga sering dikaitkan dengan keberkesanan sekolah, maka untuk meningkatkan prestasi akademik pelajar, guru harus memiliki komitmen yang tinggi terhadap sekolah (Park, 2007) kerana komitmen guru sering kali diperlukan untuk memastikan kejayaan sekolah (Ware \& Kitsantas, 2011). Guru-guru sentiasa menunjukkan komitmen yang tinggi, terutamanya terhadap pengajaran dan sekolah, juga terhadap profesion dan pelajar. Walau bagaimanapun, tahap komitmen guru tidak berbeza sama ada guru berada di sekolah berprestasi tinggi mahupun rendah. Namun demikian, guru-guru di sekolah berprestasi tinggi lebih menumpukan kepada pengajaran dan pembelajaran di dalam bilik darjah dan komitmen terhadap pengajaran ini telah mendorong kepada pencapaian akademik yang tinggi di sekolah (Mohamad, Kasim, Zakaria \& Mohd Nasir, 2016).

Di sekolah, guru merupakan modal insan profesional yang berinteraksi secara langsung dengan pelajar, maka guru seharusnya mempunyai komitmen yang tinggi agar dapat menjalankan tugasnya sebagai pendidik dengan sebaiknya. Guru yang mempunyai komitmen yang tinggi akan berasa gembira dengan tugas mendidik mereka serta kurang berminat untuk meninggalkan sekolah. Keadaan ini menggambarkan tahap komitmen guru-guru adalah tinggi, dan keadaan ini juga menunjukkan persekitaran organisasi sekolah yang baik serta memuaskan hati guru-guru. Bahkan mereka sentiasa komited dalam merealisasikan misi dan visi sekolah (Abdullah, Sekong, \& Laji, 2017) kerana untuk memastikan kejayaan organisasi semua pihak perlu saling bekerjasama dan melaksanakan tugasan masing-masing dengan penuh komitmen dan berkualiti (Abdul Razak, 2006).

Tinjauan literatur dalam bidang pendidikan sehingga kinimembuktikan bahawa iklim sekolah, sama ada secara dalaman dan luaran, perlu 
diambil kira dan dikembangkan secara holistik agar kemudahan sekolah hari ini memberikan kepuasan dan keselesaan kepada guru dalam melaksanakan tugas harian (Kariming \& Ambotang, 2018). Terdapat beberapa dimensi iklim sekolah yang mempengaruhi komitmen guru seperti kerjasama, membuat keputusan dan inovasi pengajaran. Malah, dimensi membuat keputusan dalam aspek iklim sekolah merupakan dimensi yang paling berpengaruh terhadap komitmen guru. Sekiranya pihak pentadbir sekolah ingin untuk meningkatkan komitmen para guru, pelibatan guru dalam proses membuat keputusan perlulah dipertingkatkan (Yusoff \& Saidin, 2017).

Kajian tentang iklim sekolah, prestasi serta komitmen kerja guru sangat penting dan perlu dilaksanakan secara berterusan kerana sistem pendidikan dan ilmu pendidikan sentiasa berkembang dari semasa ke semasa. Para guru perlu meningkatkan keupayaan bertaraf dunia yang diperlukan bagi membantu mencapai kemenjadian murid yang dicita-citakan, serta mencapai kepuasan dan peningkatan prestasi dan komitmen secara maksimum (Mohamed Hussin \& Ab Rahman, 2019).

\section{Iklim Sekolah}

Wirawan (2007) menjelaskan bahawa iklim organisasi adalah "konsep yang mencerminkan ciri-ciri subjektif terhadap kualiti persekitaran dalam organisasi". Iklim sekolah memiliki makna yang luas dan bergantung pada persepsi guru terhadap persekitaran kerja sekolah, sama ada sebagai organisasi formal atau tidak formal, keperibadian pihak yang terlibat, dan pengaruh guru besar atau pengetua (Sharihan \& Hussin, 2018). Iklim sekolah sebagai fenomena berkumpulan yang lebih berkesan daripada pengalaman seseorang secara individu. Malah, iklim sekolah yang positif dan lestari untuk meningkatkankan kemajuan dan pembelajaran dalam kalangan pelajar diperlukan untuk menjalani kehidupan yang produktif dan menyumbang kepada masyarakat yang demokratik (Cohen, Mccabe, \& Michelli, 2009). Iklim sekolah merupakan aspek penting dalam organisasi pendidikan (Yusoff \& Saidin, 2017). Tahap keterbukaan iklim sekolah dan keseluruhan komitmen guru adalah tinggi. Korelasi antara dimensi dalam iklim sekolah menunjukkan terdapat hubungan yang positif dengan komitmen guru. Manakala analisis regresi pula membuktikan hanya tingkah laku guru yang profesional memberikan sumbangan yang signifikan terhadap komitmen guru (Yusof, 2012). 


\section{Efikasi Kendiri}

Guru-guru mampu berdikari dalam menghasilkan pelajar dengan faktor peribadi atau guru yang baik dalam proses pengajaran (Yusoff et al., 2013). Guru perlu dibenarkan mengajar dalam persekitaran positif untuk membina keberkesanan guru yang positif (Johari et al., 2009). Pendekatan belajar dan mengajar, membuat keputusan berdasarkan data kajian tindakan, dan menyokong usaha kolaboratif menjadi peramal terhadap keberkesanan guru. Walau bagaimanapun, iklim sekolah bukan bertindak sebagai mediator terhadap efikasi kendiri guru. Tahap komitmen guru yang mempunyai efikasi kendiri adalah tinggi (Lan, 2014).

Selain itu, faktor penguat bagi komitmen organisasi terhadap efikasi kendiri guru telah dikenal pasti dalam kalangan pemimpin yang mengamalkan kepimpinan transformasional (Jazmi, 2015) dan efikasi kendiri berkaitan secara signifikan dengan komitmen guru (Cansoy, Parlar, \& Polatcan, 2020). Selain itu, efikasi kendiri juga bertindak sebagai mediator yang baik, antaranya bagi hubungan kepimpinan pengetua dan komitmen guru. Malah efikasi kendiri juga digunakan sebagai mediator untuk mengesahkan peranan hubungan antara iklim sekolah dan kepuasan kerja, dan peranan tersebut didapati positif (Katsantonis, 2020).

\section{TUJUAN DAN OBJEKTIF KAJIAN}

Kajian ini bertujuan untuk mengukur tahap iklim sekolah, efikasi kendiri dan komitmen, di samping menguji hubungan dan pengaruh yang wujud antara ketiga-tiga pemboleh ubah kajian. Manakala objektif kajian ini ialah:

1. Mengukur tahap iklim sekolah, efikasi kendiri dan komitmen.

2. Mengenal pasti hubungan antara iklim sekolah, efikasi kendiri dan komitmen.

3. Mengkaji peranan iklim sekolah sebagai peramal terhadap komitmen.

4. Menganalisis peranan efikasi kendiri sebagai mediator bagi hubungan antara iklim sekolah dengan komitmen. 


\section{METODOLOGI}

\section{Reka Bentuk Kajian dan Kerangka Kajian}

Kajian ini melaksanakan pendekatan tinjauan keratan rentas kuantitatif untuk menguji persepsi guru di sekolah berprestasi tinggi tentang iklim sekolah, efikasi kendiri, dan komitmen. Kerangka kajian pula diadaptasi berdasarkan model yang dibangunkan dalam kajian Johnson, Stevens \& Zvoch (2007) bagi iklim sekolah dan model yang dibangunkan dalam kajian Thien, Razak, dan Ramayah (2014) bagi komitmen guru. Manakala bagi efikasi kendiri, model yang dibangunkan dalam kajian Brouwers, Evers, dan Tomic (2001) telah disesuaikan untuk kajian ini. Kerangka kajian ini secara keseluruhannya direka bentuk berasaskan model kausal bermediator yang menggambarkan interaksi serta membandingkan laluan-laluan yang diperantarakan oleh pemboleh ubah mediator (efikasi kendiri) yang berada di antara pemboleh ubah tidak bersandar (iklim sekolah) dan pemboleh ubah bersandar (komitmen) (Pearl, 2014), seperti Rajah 1.

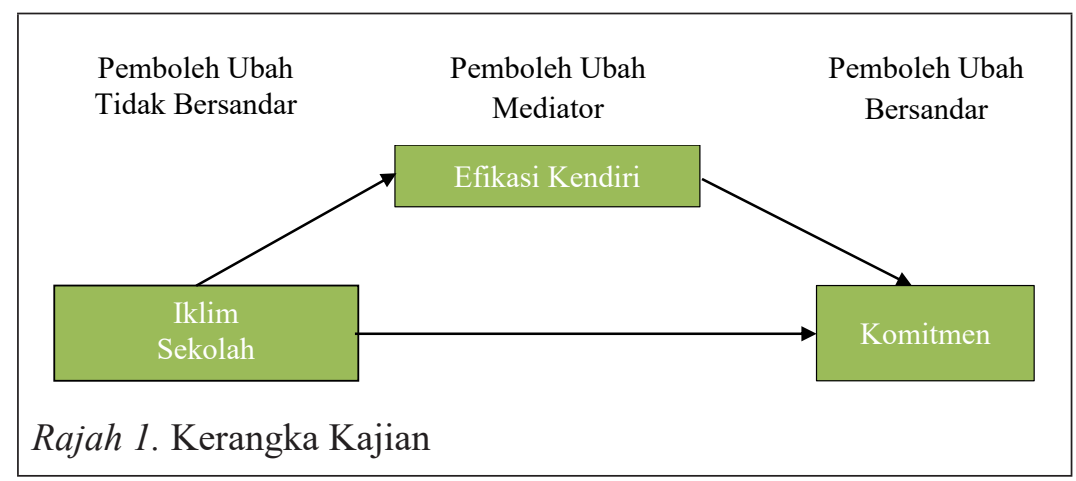

\section{Populasi dan Persampelan}

Populasi kajian ini ialah guru-guru di 18 buah sekolah menengah berprestasi cemerlang di Kelantan Pengkelasan sekolah-sekolah adalah berdasarkan Gred Purata Sekolah (GPS) dalam Sijil Pelajaran Malaysia (SPM), bagi memastikan ciri-ciri guru sebagai unit analisis dalam kategori sekolah adalah homogen. Jumlah guru di sekolah-sekolah berkenaan adalah seramai 4704 orang berdasarkan data terkini pada tahun 2019. Merujuk kepada jadual penentu saiz 
sampel Krejcie dan Morgan (1970), bilangan responden yang terlibat adalah antara seramai 354 hingga 357 orang guru. Maka, bagi tujuan tersebut, sebanyak 25 set soal selidik disediakan bagi setiap sekolah yang terlibat, dengan jumlah keseluruhan 450 set diedarkan untuk memastikan bilangan sampel adalah mencukupi. Daripada jumlah berkenaan, peratusan guru-guru yang memulangkan semula set soal selidik adalah $80.0 \%$. Memandangkan jumlah pemulangan semula soal selidik dan maklum balas yang diterima adalah agak baik, responden yang telah dipilih melalui kaedah persampelan rawak mudah dalam kajian ini adalah seramai 360 guru. Jumlah ini melebihi saiz sampel yang dicadangkan oleh Krejcie dan Morgan (1970).

Daripada keseluruhan jumlah responden seramai 360 guru, 214 orang adalah guru wanita $(59.40 \%)$ dan 146 orang adalah guru lelaki (40.60\%). Bilangan guru antara umur 31 dan 35 tahun adalah seramai 60 (16.70\%), antara 36 dan 40 tahun adalah $66(18.30 \%)$, antara 41 dan 45 tahun adalah 113 (31.40\%), antara 46 dan 50 tahun adalah $74(20.60 \%)$ dan 51 tahun berumur 47 tahun (13.10\%), seperti diperincikan dalam Jadual 1.

Jadual 1

Analisis Demografi

\begin{tabular}{clcc}
\hline Item Demografi & & Kekerapan & Peratus \\
\hline Jantina & Lelaki & 146 & 40.6 \\
& Perempuan & 214 & 59.4 \\
\multirow{2}{*}{ Umur } & $31-35$ tahun & 60 & 16.70 \\
& $36-40$ tahun & 66 & 18.30 \\
& $41-45$ tahun & 113 & 31.40 \\
& $46-50$ tahun & 74 & 20.60 \\
& 51 tahun dan ke atas & 47 & 13.10 \\
\hline
\end{tabular}

\section{Instrumen}

Instrumen untuk mengukur pemboleh ubah iklim sekolah menggunakan Teachers' Perception of School Level Environment Questionnaire (TPSLEQ) dengan 21 item. Instrumen yang mempunyai 
lima dimensi ini, iaitu kolaborasi, inovasi pengajaran, membuat keputusan, hubungan pelajar, dan sumber sekolah telah diadaptasi dari kajian oleh Johnson, Stevens, \& Zvoch (2007). Manakala instrumen untuk mengukur efikasi kendiri telah diadaptasi daripada instrumen melalui kajian Brouwers, Evers, dan Tomic (2001) dengan 18 item. Instrumen ini terdiri daripada empat dimensi, iaitu keyakinan diri dalam bimbingan berkumpulan, keyakinan diri dalam kerja pelajar, keyakinan diri dalam inovatif pendidikan dan sikap kerja di rumah. Instrumen Skala Komitmen Guru (TCS) dengan 17 item pula diadaptasi daripada Thien, Razak, dan Ramayah (2014) telah digunakan untuk mengukur pemboleh ubah komitmen. Kesemua item dalam soal selidik ini menggunakan skala selang 5-mata, iaitu antara 1-Sangat Tidak Setuju hingga 5-Sangat Setuju.

Ujian kebolehpercayaan yang telah dijalankan menunjukkan nilai kebolehpercayaan bagi efikasi kendiri $(\alpha=.96)$ sangat tinggi. Selain itu, nilai kebolehpercayaan bagi iklim sekolah $(\alpha=.82)$ dan komitmen guru $(\alpha=.87)$ adalah tinggi, dijelaskan dalam Jadual 2.

Jadual 2

Nilai Alfa Cronbach

\begin{tabular}{lccc}
\hline Pemboleh Ubah & Item & $\boldsymbol{\alpha}$ & Interpretasi \\
\hline Iklim Sekolah & 21 & .82 & Tinggi \\
Efikasi Kendiri & 18 & .96 & Sangat tinggi \\
Komitmen & 13 & .87 & Tinggi \\
\hline
\end{tabular}

Uji kenormalan dilaksanakan untuk menentukan bahawa data yang dikumpulkan adalah bertabur secara normal (Pallant, 2011), dan pengujian tersebut telah mengesahkan keperluan kenormalan. Analisis kenormalan dilakukan dengan merujuk kepada nilai skewness dan kurtosis. Hasil daripada ujian kenormalan ke atas 360 data responden menunjukkan bahawa data adalah bertabur secara normal, dengan julat yang menghampiri 0 , iaitu antara -2.00 hingga 2.00 dianggap sebagai boleh diterima sebagai taburan yang normal (George \& Mallery, 2010), memandangkan kesemua nilai skewness adalah di antara -.58 dan -.14, seperti Jadual 3. Maka analisis parametrik boleh dilaksanakan untuk mencapai objektif kajian. 
Jadual 3

Ujian Kenormalan

\begin{tabular}{lcccc}
\hline Pemboleh Ubah & Skewness & Ralat Piawai & Kurtosis & Ralat Piawai \\
\hline Iklim Sekolah & -.58 & .13 & .62 & .26 \\
Efikasi Kendiri & -.14 & .13 & -1.84 & .26 \\
Komitmen & -.42 & .13 & -1.22 & .26 \\
\hline
\end{tabular}

\section{Pengumpulan Data}

Setelah mendapatkan kebenaran daripada Bahagian Perancangan dan Penyelidikan Pendidikan (BPPDP) Kementerian Pendidikan Malaysia dan Jabatan Pelajaran Negeri Kelantan, pengkaji telah mengedarkan borang soal selidik ke sekolah-sekolah terpilih dan data kuantitatif dikumpulkan melalui soal selidik.

\section{Analisis Data}

Data yang dikutip telah analisis menggunakan ujian korelasi Pearson bagi mengenal pasti hubungan antara pemboleh ubah iklim sekolah, efikasi kendiri dan komitmen. Manakala analisis regresi linear dan berganda dilaksanakan bagi mengenal pasti pengaruh iklim sekolah sebagai peramal terhadap komitmen guru, di samping untuk menentusahkan peranan efikasi kendiri sebagai mediator bagi hubungan antara iklim sekolah dan komitmen.

\section{DAPATAN KAJIAN}

\section{Tahap Iklim Sekolah, Efikasi Kendiri dan Komitmen}

Analisis min telah dilaksanakan bagi mendapatkan interpretasi tahap iklim sekolah, efikasi kendiri dan komitmen. Nilai min ditafsirkan seperti Jadual 4. 
Jadual 4

Tafsiran Skor Min

\begin{tabular}{lc}
\hline \multicolumn{1}{c}{ Tahap } & Skor Min \\
\hline Sangat rendah & $1.00-1.80$ \\
Rendah & $1.81-2.60$ \\
Sederhana & $2.61-3.40$ \\
Tinggi & $3.41-4.20$ \\
Sangat tinggi & $4.21-5.00$ \\
\hline
\end{tabular}

$(\mathrm{UL}-\mathrm{LL}) / \mathrm{NC}=((5-1) / 5)=0.80 ; \mathrm{UL}:$ Had tertinggi, LL:Had terendah, NC: Bilangan sel (Sumber: Alotaibi et al., 2017)

Analisis deskriptif menunjukkan skor min bagi iklim sekolah ( $\mathrm{M}=4.06$, $\mathrm{SP}=.27$ ), iaitu daripada aspek kolaborasi, inovasi pengajaran, membuat keputusan, hubungan dengan pelajar dan sumber sekolah berada pada tahap tinggi. Manakala efikasi kendiri $(\mathrm{M}=4.38, \mathrm{SP}=.51)$ iaitu keyakinan diri terhadap bimbingan dalam kumpulan, tugasan murid, pendidikan berinovatif dan sikap terhadap kerja rumah berada pada tahap yang sangat tinggi. Komitmen guru yang merangkumi komitmen kepada sekolah, pelajar, pengajaran dan kerjaya sebagai guru, $(\mathrm{M}=4.36, \mathrm{SP}=.49)$ turut berada pada tahap sangat tinggi, seperti Jadual 5.

Jadual 5

Analisis Statistik Deskriptif

\begin{tabular}{lccc}
\hline \multicolumn{1}{c}{ Pemboleh Ubah } & Min & Sisihan Piawai & Tahap \\
\hline Iklim Sekolah & 4.06 & .27 & Tinggi \\
Efikasi Kendiri & 4.38 & .51 & Sangat tinggi \\
Komitmen & 4.36 & .49 & Sangat tinggi \\
\hline
\end{tabular}

\section{Hubungan Antara Iklim Sekolah, Efikasi Kendiri dan Komitmen}

Kekuatan korelasi untuk mengukur hubungan antara pemboleh ubah iklim sekolah, efikasi kendiri dan komitmen ditafsirkan seperti Jadual 6. 
Jadual 6

Tafsiran Nilai Pekali r

\begin{tabular}{cl}
\hline Nilai Pekali r & \multicolumn{1}{c}{ Tafsiran } \\
\hline 0.00 & Korelasi Tidak Wujud \\
$0.10-0.39$ & Korelasi Lemah \\
$0.40-0.69$ & Korelasi Sederhana \\
$0.70-0.99$ & Korelasi Tinggi \\
1.00 & Korelasi Sempurna \\
\hline
\end{tabular}

(Sumber: Dancey \& Reidy, 2011)

Justeru, hubungan antara pemboleh ubah iklim sekolah, efikasi kendiri dan komitmen diperoleh melalui ujian korelasi Pearson, dan nilai korelasi antara pemboleh ubah ditafsirkan berdasarkan Jadual 7.

Jadual 7

Analisis Korelasi Pearson antara Iklim Sekolah, Efikasi Kendiri dan Komitmen

\begin{tabular}{lccccc}
\hline \multicolumn{1}{c}{ Pemboleh Ubah } & Min & $\begin{array}{c}\text { Sisihan } \\
\text { Piawai }\end{array}$ & 1 & 2 & 3 \\
\hline 1. Iklim Sekolah & 4.06 & .27 & 1.00 & $.23^{* *}$ & $.24^{* *}$ \\
2. Efikasi Kendiri & 4.38 & .51 & & 1.00 & $.85^{* *}$ \\
3. Komitmen & 4.36 & .49 & & & 1.00 \\
\hline ** $<<.01$ (2-ekor) & & & & &
\end{tabular}

Nilai $r$ menunjukkan hubungan positif yang lemah (Dancey \& Reidy, 2011) antara iklim sekolah dan komitmen, $r=.24, \mathrm{n}=360, \mathrm{p}<.01$, dengan pekali penentuan, $\mathrm{r}^{2}=.06$, menunjukkan pemboleh ubah iklim sekolah menyumbang hanya $6.0 \%$ kepada tahap komitmen guru. Hubungan positif yang lemah dan signifikan juga dikesan antara iklim sekolah dan efikasi kendiri, $\mathrm{r}=.23, \mathrm{n}=360, \mathrm{p}<.01$, dengan pekali penentuan, $\mathrm{r}^{2}=.05$, yang bermaksud bahawa hanya $5 \%$ daripada tahap efikasi kendiri disumbangkan oleh perubahan iklim sekolah. Di samping itu, hubungan antara efikasi kendiri dan komitmen juga adalah signifikan, positif dan tinggi, $\mathrm{r}=.85, \mathrm{n}=360, \mathrm{p}<.01$, dengan pekali penentuan, 
$\mathrm{r}^{2}=.72$, yang bermaksud pemboleh ubah efikasi kendiri menyumbang sebanyak $72.0 \%$ kepada tahap komitmen.

\section{Iklim Sekolah Sebagai Peramal Terhadap Komitmen Guru}

Keputusan analisis regresi bagi pemboleh ubah iklim sekolah terhadap komitmen menunjukkan nilai $\mathrm{R}^{2}$ yang diperoleh ialah .06 dengan ubah suai $\mathrm{R}^{2}$ ialah .06. Ini menunjukkan bahawa $6.0 \%$ varians komitmen dapat dijelaskan oleh pemboleh ubah iklim sekolah. Keputusan statistik menunjukkan bahawa nilai $\mathrm{F}=21.79, \mathrm{p}<.01$ adalah signifikan. Dapatan ini menunjukkan bahawa model regresi iklim sekolah adalah signifikan dan boleh diterima pakai untuk menerangkan varians bagi komitmen, seperti ditunjukkan dalam Jadual 8.

Jadual 8

Analisis Regresi Linear bagi Iklim Sekolah dan Komitmen

\begin{tabular}{ccccc}
\hline Model & $\mathrm{R}$ & $\mathrm{R}^{2}$ & ${\text { Ubah Suai } \mathrm{R}^{2}}$ & Ralat Piawai \\
\hline 1 & .24 & .06 & .06 & .47 \\
\hline
\end{tabular}

a. Peramal: (Konstan), Iklim Sekolah

b. Pemboleh Ubah Bersandar: Komitmen

Hasil analisis menunjukkan bahawa secara signifikan, iklim sekolah $(\beta=.24, \mathrm{p}<.01)$ menyumbang sebanyak $6.0 \%\left(\mathrm{R}^{2}=.06\right)$ perubahan varians dalam komitmen $[\mathrm{F}(2,357)=21.79, \mathrm{p}<.01]$, dijelaskan dalam Jadual 9.

Jadual 9

Analisis ANOVA bagi Iklim Sekolah dan Komitmen

\begin{tabular}{ccccccc}
\hline & Model & Jumlah Kuasa & Darjah & Min Kuasa & F & Signifikan \\
& & Dua & Kebebasan & Dua & & \\
\hline \multirow{2}{*}{1} & Regresi & 4.86 & 4.86 & 4.86 & 21.79 & $0.00 \mathrm{~b}$ \\
& Residual & 79.78 & 79.78 & .22 & & \\
& Jumlah & 84.64 & 84.64 & & & \\
\hline
\end{tabular}

a. Pemboleh Ubah Bersandar: Komitmen

b. Peramal: (Konstan), Iklim Sekolah 
Sumbangan pemboleh ubah peramal iklim sekolah ditunjukkan dalam nilai pekali piawai (standard coefficient). Nilai beta bagi sumbangan iklim sekolah adalah $\beta=.24$ (24.0\%), secara signifikan mempengaruhi komitmen, dengan nilai $\mathrm{p}<.01$, seperti Jadual 10.

Jadual 10

Output Pekali Piawai

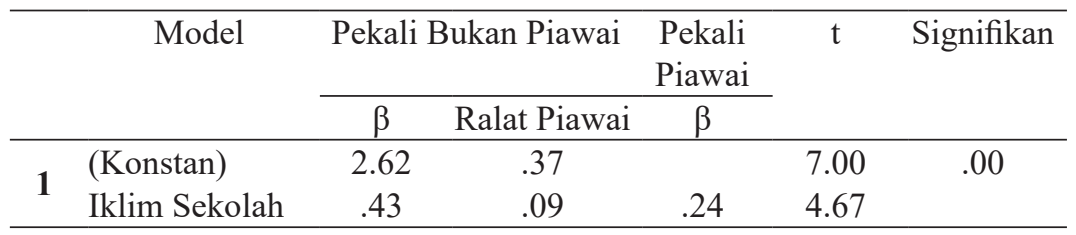

a. Pemboleh Ubah Bersandar: Komitmen

Maka, model persamaan regresi yang sesuai digunakan bagi meramal tahap komitmen di sekolah ialah: Komitmen $=2.62+.43(\mathrm{Iklim}$ Sekolah) $+e(4.67) * *$.

\section{Efikasi Kendiri Sebagai Mediator bagi Hubungan Antara Iklim Sekolah Dengan Komitmen}

Analisis regresi berganda bagi iklim sekolah dan efikasi kendiri terhadap komitmen menunjukkan bahawa $\mathrm{R}^{2}=.72$, yang menjelaskan nilai variasi bagi komitmen yang dipengaruhi oleh perubahan peramal iklim sekolah dan efikasi kendiri ialah 72.0\%, seperti Jadual 11.

Jadual 11

Analisis Regresi Berganda bagi Iklim Sekolah, Efikasi Kendiri dan Komitmen

\begin{tabular}{ccccc}
\hline Model & $\mathrm{R}$ & $\mathrm{R}^{2}$ & Ubah Suai $^{2}$ & Ralat Piawai \\
\hline 1 & .85 & .72 & .72 & .26 \\
\hline
\end{tabular}

a. Peramal: (Konstan), Efikasi Kendiri, Iklim Sekolah

b. Pemboleh Ubah Bersandar: Komitmen

Nilai analisis menunjukkan bahawa model ini adalah signifikan, seperti Jadual 12. 
Jadual 12

Analisis ANOVA bagi Iklim Sekolah, Efikasi Kendiri dan Komitmen

\begin{tabular}{cccccc}
\hline Model & $\begin{array}{c}\text { Jumlah Kuasa } \\
\text { Dua }\end{array}$ & $\begin{array}{c}\text { Darjah } \\
\text { Kebebasan }\end{array}$ & $\begin{array}{c}\text { Min Kuasa } \\
\text { Dua }\end{array}$ & F & Signifikan \\
\hline Regresi & 60.87 & 2 & 30.44 & 457.19 & $0.00 \mathrm{~b}$ \\
Residual & 23.77 & 357 & .07 & & \\
Jumlah & 84.64 & 359 & & & \\
\hline
\end{tabular}

a. Pemboleh Ubah Bersandar: Komitmen

b. Peramal: (Konstan), Efikasi Kendiri, Iklim Sekolah

Sumbangan pemboleh ubah peramal iklim sekolah dan efikasi kendiri ditunjukkan dalam nilai pekali piawai (standard coefficient). Nilai beta menunjukkan bahawa sumbangan iklim sekolah berkurang kepada $\beta=.05$ (5.0\%), serta tidak lagi secara signifikan mempengaruhi komitmen, dengan nilai $\mathrm{p}>.05$, apabila pemboleh ubah peramal efikasi kendiri dimasukkan ke dalam model regresi. Manakala nilai beta menunjukkan bahawa sumbangan efikasi kendiri, $\beta=.84(84.0 \%)$ mempengaruhi komitmen, dan nilai ini adalah signifikan dengan $\mathrm{p}<.01$. Maka, efikasi kendiri dikenal pasti sebagai pemboleh ubah mediator dengan kesan mediator penuh memandangkan pengaruh iklim sekolah berkurang dan tidak lagi signifikan apabila efikasi kendiri dimasukkan ke dalam model, seperti Jadual 13.

Jadual 13

Output Pekali Piawai

\begin{tabular}{llccccc}
\hline \multirow{2}{*}{ Model } & \multicolumn{2}{c}{ Pekali Bukan Piawai } & Pekali Piawai & \multirow{2}{*}{ Signifikan } \\
\cline { 2 - 5 } & $\beta$ & Ralat Piawai & $\beta$ & & \\
\hline \multirow{2}{*}{ (Konstan) } & .55 & .22 & & 2.54 & .01 \\
Iklim Sekolah & .08 & .05 & .05 & 1.59 & .11 \\
Efikasi Kendiri & .79 & .03 & .84 & 29.01 & .00 \\
\hline
\end{tabular}

a. Pemboleh Ubah Bersandar: Komitmen

Maka, model persamaan regresi yang sesuai digunakan bagi meramal tahap komitmen di sekolah ialah: Komitmen $=0.55+.79$ (Efikasi Kendiri $)+.08($ Iklim Sekolah $)+e(29.01) * *(1.59)$. 


\section{PERBINCANGAN}

Secara keseluruhan, dapatan kajian ini menunjukkan bahawa tahap iklim di sekolah, iaitu daripada aspek kolaborasi, inovasi pengajaran, membuat keputusan, hubungan dengan pelajar dan sumber sekolah adalah tinggi. Manakala tahap efikasi kendiri, iaitu berkenaan dengan keyakinan diri terhadap bimbingan dalam kumpulan, tugasan murid, pendidikan berinovatif dan sikap terhadap kerja rumah adalah sangat tinggi. Begitu juga dengan komitmen guru di sekolahsekolah berkenaan turut berada pada tahap yang sangat tinggi, iaitu merangkumi komitmen kepada sekolah, pelajar, pengajaran dan kerjaya sebagai guru. Oleh itu, keyakinan dan kebersamaan yang ditunjukkan oleh para guru mampu membuahkan kecemerlangan dalam pelbagai aspek di sekolah.

Kajian ini juga menyatakan bahawa iklim sekolah mempunyai korelasi lemah serta positif dan signifikan terhadap efikasi kendiri dan komitmen, yang menjelaskan semakin tinggi iklim sekolah, semakin tinggi efikasi kendiri dan komitmen guru di sekolah walaupun pada skala yang kecil. Tahap efikasi kendiri yang tinggi adalah hasil dimensi dialog reflektif bagi mewujudkan iklim sekolah yang menyenangkan. Komunikasi yang berkesan dan lebih kerap dengan rakan sekerja dalam proses pengajaran dan pembelajaran mampu mempengaruhi guru kepada organisasi sekolah yang praktikal, yang secara keseluruhannya pada tahap yang lebih tinggi. Penemuan ini menunjukkan bahawa persekitaran sosial yang menyokong memberi keyakinan yang lebih besar kepada guru terhadap kemampuan rakan rakan sekerja (Lim \& Eo, 2014).

Persepsi guru terhadap motivasi dan tingkah laku pelajar menunjukkan kesan paling besar bagi faktor iklim sekolah. Malah pemboleh ubah tersebut adalah peramal kepada tekanan, efikasi kendiri, dan kepuasan kerja yang signifikan dalam kalangan guru (Collie, Shapka, \& Perry, 2012; Hosford \& Sullivan, 2015). Terdapat beberapa dimensi iklim sekolah mempengaruhi komitmen guru, seperti kolaborasi, membuat keputusan, dan inovasi pengajaran. Dimensi membuat keputusan adalah dimensi komitmen guru yang paling penting (Yusoff \& Saidin, 2016). Sekiranya pihak pengurusan sekolah bertujuan untuk meningkatkan komitmen guru, pelibatan guru dalam proses membuat 
keputusan perlu ditingkatkan (Raman, Ling, \& Rozalina Khalid, 2015).

Selain itu, efikasi kendiri dan komitmen guru berkorelasi positif pada tahap tinggi, dan hubungan ini signifikan. Satu model berstruktur telah dibangunkan dan mengesahkan bahawa hubungan antara efikasi kendiri dan komitmen guru yang didapati dalam kajian sebelumnya. Keberkesanan guru terhadap arahan pentadbiran, keberkesanan membuat keputusan, dan kawalan terhadap aspek operasi bilik darjah telah meningkatkan komitmen guru (Ware \& Kitsantas, 2011). Melalui lensa kepuasan, autonomi, sokongan, dan efikasi kendiri dalam kalangan guru telah membentuk motivasi guru terhadap komitmen dan penambahbaikan berterusan terhadap kerjaya mengajar (Ford, Sickle, Clark, Fazio-brunson, \& Schween, 2015). Selain itu, efikasi yang positif berkorelasi secara statistikal dan praktikal, malah signifikan dengan ukuran kesan sederhana terhadap komitmen guru dalam profesion perguruan (Ford et al., 2015).

Melalui hubungan langsung, iklim sekolah menjadi peramal yang mempengaruhi komitmen guru secara signifikan. Iklim sekolah menjadi fokus tumpuan serta perhatian di semua organisasi pendidikan kerana telah memberikan sumbangan positif terhadap komitmen guru (Raman et al., 2015). Selain itu, tahap keterbukaan iklim sekolah dan komitmen guru secara keseluruhan adalah tinggi. Bagi hubungan antara dimensi iklim sekolah dan komitmen guru, hasilnya menunjukkan hubungan positif dan signifikan. Walau bagaimanapun, analisis regresi menunjukkan bahawa hanya tingkah laku profesional guru yang memberikan sumbangan besar terhadap komitmen guru (Yusof, 2012).

Di samping itu, kesan mediator juga telah dikenal pasti bagi hubungan antara iklim sekolah dan komitmen guru. Pengaruh iklim sekolah terhadap komitmen guru tidak lagi signifikan apabila pemboleh ubah efikasi kendiri dilaksanakan dalam model. Oleh itu, kesan mediator sepenuhnya telah dikenal pasti. Oleh itu, efikasi kendiri disahkan sebagai pemboleh ubah mediator bagi hubungan antara iklim sekolah dengan komitmen guru dengan kesan mediator penuh. Kajian oleh Lim dan Eo (2014) dan Chan, Shun Lau Nie, Lim, dan Hogan (2008) juga menyatakan bahawa efikasi kendiri adalah merupakan pemboleh 
ubah mediator. Selain itu, satu model struktur telah dibangunkan dan menunjukkan bahawa iklim sekolah telah memberikan kesan positif, yang sebahagiannya diperantarakan oleh efikasi kendiri terhadap kepuasan kerja. Malah, efikasi kendiri dan efikasi kolektif dalam kajian tersebut juga bertindak sebagai mediator (Malinen dan Savolainen, 2016).

\section{KESIMPULAN DAN IMPLIKASI}

Kajian ini diharap dapat memberikan pendedahan yang bermakna kepada pihak pentadbiran sekolah khususnya dan organisasi pendidikan amnya dalam memahami dengan lebih mendalam tentang iklim sekolah, efikasi kendiri dan komitmen guru. Dapatan kajian ini membantu guru dan pihak pentadbir sekolah agar dapat mengenal pasti dan sentiasa peka dan cakna terhadap faktor iklim sekolah yang mampu meningkatkan komitmen guru. Selain itu, kajian ini juga merumuskan bahawa komitmen guru dapat ditingkatkan melalui wujudnya efikasi kendiri guru yang kuat. Guru-guru yang mempunyai keyakinan diri yang tinggi terhadap bimbingan dalam kumpulan, tugasan murid, pendidikan berinovatif dan sikap terhadap kerja rumah berupaya mengembangkan tahap komitmen di sekolah. Penemuan tersebut menunjukkan bukti yang signifikan dan menggambarkan hubungan positif iklim sekolah terhadap efikasi kendiri dan komitmen guru. Malah, dengan adanya efikasi kendiri yang cemerlang pada setiap guru, guru-guru mampu komited terhadap kerjaya mereka tanpa mengira keadaan iklim di sekolah. Peranan mediator penuh bagi pemboleh ubah efikasi kendiri ini telah mendorong guru secara kognitif supaya guru lebih bermotivasi untuk bertindak secara terarah bagi mencapai tujuan yang jelas di sekolah.

Kajian ini telah menyumbang terhadap teori dan bidang ilmu secara signifikan dengan menjelaskan peranan iklim sekolah, begitu juga dengan peranan efikasi kendiri sebagai mediator yang turut menyumbang kepada komitmen guru dalam meningkatkan kecemerlangan sekolah serta memberikan implikasi dari pelbagai aspek. Dari aspek teori, diharapkan kajian ini dapat menyumbang kepada pembangunan dan perkembangan literatur tentang iklim 
sekolah, efikasi kendiri dan komitmen, khususnya di sekolah menengah yang mempunyai pencapaian akademik yang tinggi. Selain itu, dari aspek dasar, pihak yang terlibat perlu sentiasa cakna dengan perkembangan dan kesejahteraan institusi pendidikan, agar iklim sekolah dapat dibentuk secara lebih praktikal dan kondusif, serta mempersiapkan latihan dan bimbingan secara berterusan kepada para pengetua. Dari aspek amalan pula, semua pemimpin sekolah seharusnya memastikan semua amalan terbaik tentang iklim sekolah dilaksanakan di intitusi masing-masing mengikut kesesuaian, agar secara tidak langsung mampu merangsang efikasi kendiri dan komitmen guru dengan lebih baik.

Selain itu, kajian masa depan seharusnya mempertimbangkan pemboleh ubah lain untuk dimasukkan ke dalam kajian untuk meningkatkan kesan komitmen guru. Sama ada pemboleh ubah ini akan bertindak sebagai mediator atau moderator, kewujudan pemboleh ubah baru perlu diberika perhatian dan fokus yang lebih mendalam. Selain itu, analisis model berstruktur harus dikembangkan untuk menguji pengaruh ketiga-tiga pemboleh ubah, iaitu iklim sekolah, efikasi kendiri, dan komitmen guru, bagi menambah baik model ini agar dapat meningkatkan komitmen guru di sekolah secara efektif. Kajian ini memberikan sumbangan yang signifikan terhadap komitmen dan efikasi kendiri guru dalam meningkatkan kejayaan dan keberkesanan sekolah.

Kesimpulannya, kajian harus sentiasa dilaksanakan bagi mendapatkan data daripada para guru untuk menentukan penilaian kendiri terhadap iklim sekolah dalam membentuk efikasi kendiri yang baik dan meningkatkan komitmen guru. Kajian terhadap iklim sekolah ke arah memastikan persekitaran kerja yang baik dapat diamalkan dan ditingkatkan, serta sama ada iklim sekolah yang kondusif mampu mengubah keberkesanan guru baik dari segi efikasi kendiri mahupun komitmen, adalah bermanfaat untuk dilaksanakan.

\section{PENGHARGAAN}

Penyelidikan ini tidak mendapat geran khusus dari mana-mana agensi pembiayaan di sektor awam atau komersial. 


\section{RUJUKAN}

Abdul Razak, A. Z. (2006). Ciri iklim sekolah berkesan: Implikasinya terhadap motivasi pembelajaran. Jurnal Pendidikan. 31. 3-19.

Abdullah, M. K., Sekong, M. \& Laji, H. (2017). Kecerdasan emosi dan komitmen guru terhadap organisasi. Jurnal Psikologi dan Kesihatan Sosial (JPsiKS). 1. 42-52.

Bandura, A. (1995). Self-efficacy in changing societies. Cambridge University Press. http://doi.org/https://doi.org/10.1017/CBO97805 11527692

Brouwers, A., Evers, W. J. G., \& Tomic, W. (2001). Self-efficacy in eliciting social support and burnout among secondary-school teachers. Journal of Applied Social Psychology, 31 (7), 14741491.

Cansoy, R., Parlar, H., \& Polatcan, M. (2020). Collective teacher efficacy as a mediator in the relationship between instructional leadership and teacher commitment. International Journal of Leadership in Education, 1-19. http://doi.org/10.1080/ 13603124.2019.1708470

Chan, W., Shun Lau Nie, Y., Lim, S., \& Hogan, D. (2008). Organisational and personal predictors of teacher commitment: The mediating role of teacher efficacy and identification with school. American Educational Research Journal, 45 (3), 597630. http://doi.org/10.3102/ 0002831208318259

Cohen, J., Mccabe, E. M., \& Michelli, N. M. (2009). School climate: Research, policy, practise, and teacher education. Teachers College Record, 111(1), 180-213.

Collie, R. J., Shapka, J. D., \& Perry, N. E. (2012). School climate and social-emotional learning: Predicting teacher stress, job satisfaction, and teaching efficacy. Journal of Educational Psychology, 104 (4), 1189-1204. http://doi.org/10.1037/a0029356

Dancey, C., \& Reidy, J.(2011). Statistics without maths for psychology. Book (5th ed.). Rotolito Lombarda, Italy: Prentice-Hall.

Daud, Y. (2007). Budaya sekolah rendah: Hubungannya dengan kepemimpinan, komitmen organisasi dan pencapaian akademik.

Ford, T. G., Sickle, M. E. Van, Clark, L. V, Fazio-brunson, M., \& Schween, D. C. (2015). Teacher self-efficacy, professional commitment, and high-stakes teacher evaluation policy in Louisiana. Educational Policy, 1-47. http://doi.org/10.1177/ 0895904815586855 
George, D., \& Mallery, M. (2010). SPSS for Windows Step by Step: A Simple Guide and Reference, 17.0. update (10a ed.) Boston: Pearson.

Hallinger, Philip, and R. H. Heck. 2010a. Collaborative leadership and school improvement: understanding the impact on school capacity and student learning. School Leadership and Management. 30 (2). 95-110.

Haron, S. \& Wan Jaafar, W. M. \& Baba, M. (2010). The influence of school climate towards counselor's self-efficacy. Procedia Social and Behavioral Sciences. 5. 445-448. 10.1016/j. sbspro.2010.07.120.

Hauschildt, K. \& Konradt, U. (2012). Self-leadership and team members' work role performance. Journal of Managerial Psychology. 27. 497-517. 10.1108/02683941211235409.

Hinton, P. R., McMurray, I., Brownlow, C., \& Cozens, B. (2004). SPSS Explained (1st ed.). London, United Kingdom: Routledge.

Hosford, S., \& Sullivan, S. O. (2015). A climate for self-efficacy: the relationship between school climate and teacher efficacy for inclusion. International Journal of Inclusive Education, ISSN, 1-17. http://doi.org/10.1080/13603116.2015.1102339

Jazmi, M. I. (2015). Pengaruh kepimpinan transformasi pengetua tahap komitmen organisasi dan efikasi kendiri guru sekolahsekolah Agama di Kedah. Universiti Utara Malaysia. Retrieved from http://etd.uum.edu.my/id/eprint/5359

Johari, K., Ismail. Z., Osman, S. \& Othman, A. T. (2009). Pengaruh jenis latihan guru dan pengalaman mengajar terhadap efikasi guru sekolah menengah. Jurnal Pendidikan Malaysia, 34 (2), 3-14.

Johnson, B. P., Stevens, J. J., \& Zvoch, K. (2007). Teachers' perceptions of school climate: A validity study of scores from the revised school level environment questionnaire. Educational and Psychological Measurement, 67 (5), 833-844. http://doi.org/ https://doi.org/10.1177/ 0013164406299102

Kariming, N. F.A \& Ambotang, A. S. (2018). Hubungan iklim sekolah terhadap kepuasan kerja guru Tingkatan 6 Zon Pantai Timur Sabah. Jurnal Komunikasi Borneo, 6, 53-64.

Katsantonis, I. G. (2020). Investigation of the impact of school climate and teachers' self-efficacy on job satisfaction: A crosscultural approach. European Journal of Investigation in Health, Psychology and Education, 119-133. 
KPM. (2012). Laporan Awal Pelan Pembangunan Pendidikan Malaysia 2013-2025. Putrajaya: Kementerian Pendidikan Malaysia.

Krejcie, R. T. \& Morgan, D. W. (1970). Determining sample size for research activities. Educational And Psychological Measurement, 30. 607-610.

Lan, S. (2014). The relationships between instructional leadership behaviour, school climate, and teacher efficacy in secondary schools in Kedah. Universiti Utara Malaysia, Kedah.

Lim, S., \& Eo, S. (2014). The mediating roles of collective teacher efficacy in the relations of teachers' perceptions of school organisational climate to their burnout. Teaching and Teacher Education, 44, 138-147. http://doi.org/10.1016/j. tate.2014.08.007

Malinen, O., \& Savolainen, H. (2016). The effect of perceived school climate and teacher efficacy in behaviour management on job satisfaction and burnout: A longitudinal study. Teaching and Teacher Education, 60, 144-152. http://doi.org/10.1016/j. tate.2016.08.012

Mansor, A. M. \& Dali, H. (2016). Hubungan dan kesan kepimpinan kendiri guru terhadap gelagat kewarganegaraan organisasi. Proceeding of ICECRS, 1, 753-768. International Seminar on Generating Knowledge Through Research, UUM-UMSIDA, DOI: http://dx.doi.org/10.21070/picecrs.v1i1.548

Mohamad, R., Kasim, A. L., Zakaria, S. \& Mohd Nasir, F. (2016). Komitmen guru dan kepuasan kerja guru di sekolah menengah harian berprestasi tinggi dan berprestasi rendah di Daerah Kota Bharu, Kelantan. Proceeding of ICECRS, 1, 863-874. International Seminar on Generating Knowledge Through Research, UUM-UMSIDA, DOI:http://ojs.umsida.ac.id/ index. php/icecrs, doi: http://dx.doi.org/10.21070/picecrs.v1i1.603

Mohamed Hussin, M. S. \& Ab Rahman, R. (2019). Kepentingan iklim sekolah dalam mempengaruhi prestasi dan komitmen kerja guru. Journal of Management and Operation Research, 1 (24). 1-8.

Othman Talib. (2015). SPSS Analisis data kuantitatif untuk penyelidik muda (2nd Ed.). Bangi, Selangor: MPWS Rich Publication.

Pallant, J. (2011). SPSS Survival manual (4th Ed.). Everbest Printing. 
Park, I. (2007). Teacher commitment and its effects on student achievement in American high schools. Educational Research andEvaluation: AnInternationalJournalon TheoryandPractice, 11 (5), 461-485. http://doi.org/10.1080/13803610500146269

Pearl, J. (2014). Interpretation and identification of causal mediation. Psychological Methods. American Psychological Association, 19 (4). 459-481.

Raman, A., Ling, C. C., \& Rozalina Khalid. (2015). Relationship between school climate and teachers' commitment in an excellent school of Kubang Pasu District, Kedah, Malaysia. Mediterranean Journal of Social Sciences, 6 (3), 163-173. http://doi.org/10.5901/mjss.2015.v6n3s1p163

Shafiq, M., \& Rana, R. A. (2016). Relationship of emotional intelligence to organisational commitment of college teachers in Pakistan. Eurasian Journal of Educational Research, (62), 1-14. http://doi.org/10.14689/ejer.2016.62.1

Sharihan, M., \& Hussin, M. (2018). Peranan iklim sekolah dalam meningkatkan prestasi kerja guru: Satu ulasan. International Journal of Education, Psychology and Counseling, 3 (18), 87-93.

Thien, L. M., Razak, N. A., \& Ramayah, T. (2014). Validating teacher commitment scale using a Malaysian sample. SAGE Open, 1-9. http://doi.org/10.1177/2158244014536744

Wan Ismail, W. R. \& Kassim, M. (2015). Amalan kepemimpinan pengajaran penolong kanan kurikulum, iklim sekolah, sikap kerja guru dan komitmen organisasi di sekolah menengah kebangsaan. Jurnal Pedagogik Pendidikan Dasar, 3 (1). 63 73.

Ware, H. W., \& Kitsantas, A. (2011). Predicting teacher commitment using principal and teacher efficacy variables: An HLM approach. The Journal of Educational Research, 104 (3), 183193. http://doi.org/10.1080/00220671003638543

Wirawan. (2007). Budaya dan iklim organisasi: Teori aplikasi dan penelitian. Salemba Empat.

Yusof, M. M., Muda, A., Abdullah, A. M., Abu Samah, B., Basri, R. \& A. Rashid, N. (2013). Faktor-faktor yang mempengaruhi efikasi kendiri guru sekolah menengah di Malaysia dalam pelaksanaan Pendidikan Alam Sekitar. Asia Pacific Journal of Educators and Education, 28, 131-153. 
Practitioner Research Vol. 2, July, 2020, 137-162

Yusof, N. M. (2012). School climate and teachers' commitment: A case study of Malaysia. International Journal of Economics, Business and Management Studies, 1 (2), 65-75.

Yusoff, S. M. \& Saidin, K. (2017). Tahap iklim sekolah, Tahap komitmen guru serta hubungan di antara iklim sekolah dengan komitmen guru sekolah-sekolah menengah Daerah Machang, Kelantan. Proceedings of the ICECRS, 1 (1). pp. 635-646. ISSN 2548-6160.

Zainudin Awang. (2014). Research methodology and data analysis (2nd ed.). Subang Jaya, Selangor: UiTM Press. 